\title{
Real Time Derivation of Atmospheric Aerosol Optical Properties by Concurrent Measurements of Optical and Sampling Instruments
}

\author{
Jamrud Aminuddin',2, Shin'ichiro Okude¹, Nofel Lagrosas', Naohiro Manago', Hiroaki Kuze1 \\ ${ }^{1}$ Center for Environmental Remote Sensing, Chiba University, Chiba, Japan \\ ${ }^{2}$ Department of Physics, Faculty of Mathematics and Natural Science, Universitas Jenderal Soedirman, Purwokerto, Indonesia \\ Email: jamrud.aminuddin@unsoed.ac.id, jamrud.aminuddin@chiba-u.jp
}

How to cite this paper: Aminuddin, J., Okude, S., Lagrosas, N., Manago, N. and Kuze, H. (2018) Real Time Derivation of Atmospheric Aerosol Optical Properties by Concurrent Measurements of Optical and Sampling Instruments. Open Journal of Air Pollution, 7, 140-155.

https://doi.org/10.4236/ojap.2018.72008

Received: May 28, 2018

Accepted: June 25, 2018

Published: June 28, 2018

Copyright $\odot 2018$ by authors and Scientific Research Publishing Inc. This work is licensed under the Creative Commons Attribution International License (CC BY 4.0).

http://creativecommons.org/licenses/by/4.0/

(c) (i) Open Access

\begin{abstract}
The understanding of aerosol properties in troposphere, especially their behavior near the ground level, is indispensable for precise evaluation of their impact on the Earth's radiation studies. Although a sunphotometer or a skyradiometer can provide the aerosol optical thickness (AOT), their application is limited to daytime under near cloud free conditions. In order to attain the multi-wavelength observation for both day- and night-time including cloudy conditions, here we propose a novel monitoring technique by means of simultaneous measurement using a nephelometer (450,550, and $700 \mathrm{~nm}$ ), an aethalometer $(370,470,520,590,660,880$, and $950 \mathrm{~nm})$, and a visibility meter $(550 \mathrm{~nm})$. On the basis of the multi-wavelength data of scattering and absorption coefficients from the nephelometer and aethalometer, respectively, first we calculate the real-time values of aerosol extinction coefficient in addition to the Angstrom exponent (AE). Then, correction of these values is carried out by comparing the resulting extinction coefficient with the corresponding value obtained from the optical data of visibility-meter. The major reason for this correction is the loss of relatively coarse particles due to the aerodynamic effect as well as evaporation of water content from particles during the sampling procedure. Then, with the ancillary data of vertical aerosol profile obtained with a lidar $(532 \mathrm{~nm})$, the temporal change of AOT is estimated. In this way, information from the sampling can be converted to the ambient properties in the atmospheric boundary layer. Furthermore, daytime data from a sunphotometer $(368,500,675$, and $778 \mathrm{~nm})$ and a skyradiometer $(340,380$, $400,500,675,870$, and $1020 \mathrm{~nm}$ ) are used to validate the resulting AOT values. From the overall procedure, we can estimate the AE and AOT values
\end{abstract}


from the sampling data, with uncertainties of approximately $5 \%$ for $\mathrm{AE}$ and $10 \%$ for AOT. Such a capability will be useful for studying aerosol properties throughout 24 hours regardless of the solar radiation and cloud coverage.

\section{Keywords}

Aerosol Optical Thickness, Angstrom Exponent, Extinction Coefficient, Sampling Measurement, Optical Measurement

\section{Introduction}

The importance of both direct and indirect effects of gaseous pollutants and aerosols to the atmosphere has been discussed in the context of the earth radiation budget and global climate change [1] [2]. The precise measurement of aerosol parameters is important for increasing the level of understanding of their characteristics, especially in the lower troposphere where most of the emission sources are located. In addition to various sampling measurements, optical remote sensing has widely been used to monitor and analyze aerosol optical properties [3].

The most fundamental parameters that are used to describe the optical influence of aerosol particles are the extinction coefficient and optical thickness. For vertical measurements, aerosol extinction coefficient (AEC) is given as a function of altitude, $z$, and wavelength, $\lambda$, representing the light attenuation due to the combined effects of scattering and absorption [4] [5] [6]. Aerosol optical thickness (AOT) usually refers to the integration of extinction coefficient over the whole range of altitude, from the surface to the top of the atmosphere [6] [7] [8] [9] [10]. Values of AOT can be obtained from measurements using instruments such as a sunphotometer calibrated by means of the Langley extrapolation method [8] [9] [10], and the information on AOT with its wavelength dependence is valuable for monitoring the influence of aerosols and clouds [10] [11] [12]. The use of a sunphotometer, however, is limited to daytime under nearly cloud free conditions when the observation of the directly transmitted solar radiation is feasible.

To attain the multi-wavelength observation of aerosol optical thickness near the surface level regardless of the cloud coverage conditions, here we propose a novel monitoring technique based on measurements of scattering coefficient, absorption coefficient, and visibility for calculating AOT. To obtain such aerosol parameters, and concurrent measurement data from a multi-wavelength integrating nephelometer (scattering coefficient), a multi-wavelengthaethalometer (absorption coefficient), and a visibilitymeter are exploited. Such measurements are routinely conducted at the Center for Environmental Remote Sensing (CEReS), Chiba University, Japan. The validation of the resulting AOT, on the other hand, is carried out using the data of a sunphotometer, and also operated at CEReS. The continuous estimation of AOT near the surface is considered to 
be useful for studying sources and sinks of aerosol particles in relation to the monitoring of local environment [13].

The remaining part of this paper is organized as follows. In Section 2, the instrumentation is given, whereas in Section 3, the methodology is described. Section 4 gives the results and discussion, followed by the conclusion section.

\section{Instrumentation}

All the sampling and optical data used in this study are obtained from instruments operated on the campus of Chiba University $\left(35^{\circ} 37^{\prime} 30^{\prime \prime} \mathrm{N}\right.$ and $\left.140^{\circ} 06^{\prime} 14^{\prime \prime} \mathrm{E}\right)$. The university is in the mid of Chiba city, which in turn is located on the east coast of Tokyo Bay (Figure 1). The aerosol characteristics in Chiba were investigated in our previous studies [14] [15]. Briefly, the dominance of coarse particles is seen due mainly to sea salt particles from the Tokyo Bay area during the summer season. During the winter season, on the other hand, contribution of fine mode particles becomes more significant due to urban activities. On average, the AOT values are relatively higher and lower in summer and winter, respectively.

For the sampling measurement, a 3-m long vertical pipe made of stainless steel is used as an inlet of aerosol particles from the ambient atmosphere on the rooftop of an eight-story building of CEReS. An integrating nephelometer (TSI3563) provides the scattering coefficients measured at the three wavelengths of 450, 550, and $700 \mathrm{~nm}$. An aethalometer (Magee, AE31) measures the black carbon (BC) concentration values at the seven wavelengths of 370, 470, 520, 590, 660,880 , and $950 \mathrm{~nm}$. In addition to these sampling instruments, a visibility meter (Vaisala, PWD52) is operated to measure the meteorological visibility on the same rooftop, approximately $30 \mathrm{~m}$ above the surface level $(50 \mathrm{~m}$ above sea level). The visibility value provided from this instrument is the value that has been converted to the wavelength of $550 \mathrm{~nm}$, though its operational wavelength is $875 \mathrm{~nm}$. The data from these instruments are employed to derive the AOT value

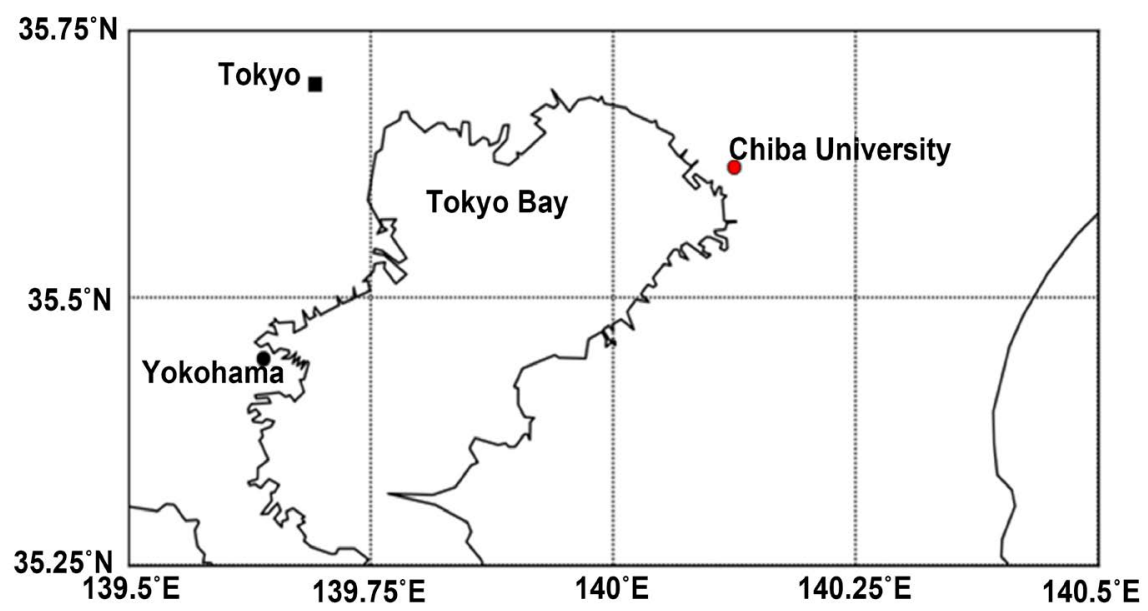

Figure 1. The location of ground based instrument and lidar systems in Chiba University-Japan. 
throughout day- and night time, with ancillary information from a dual wavelength (532 and $1064 \mathrm{~nm}$ ) lidar of National Institute for Environmental Research (NIES), operated also on the Chiba University campus (NIES Chiba lidar). Besides, the supporting information on the local weather is obtained from a weather monitor (Davis, Vantage Pro). Also these instruments are routinely operated as CEReS facilities.

For the purpose of validating the resulting AOT, we exploit the data from a sun photometer (Prede, PSF-100) $(368,500,675$, and $778 \mathrm{~nm})$ and a sky radiometer (Prede, POM-02) (340, 380, 400, 500, 675, 870, and $1020 \mathrm{~nm})$. This latter instrument is operated as part of the SKYNET, an international network of radiation-measurement instruments used for recording and characterizing regional properties of aerosol, cloud, and solar radiation [16] [17].

\section{Methods}

Here we explain the theoretical basis how the instrumental data near the surface level can be converted into the estimated values of AOT. The value of AEC, $\alpha_{e x t}^{S}(\lambda)$ is computed as [3] [7]

$$
\alpha_{e x t}^{S}(\lambda)=\alpha_{s c a}(\lambda)+\alpha_{a b s}(\lambda)
$$

where the superscript $S$ indicates the value from the sampling measurement. The scattering coefficient, $\alpha_{s c a}(\lambda)$, can readily be obtained from the integrating nephelometer. The absorption coefficient, $\alpha_{a b s}(\lambda)$, can be calculated from the $B C$ (black carbon) concentration data of the aethalometer as

$$
\alpha_{a b s}(\lambda)=\left(B C(\lambda) \times 10^{-9}\right) \frac{6834}{\lambda} .
$$

Here the conversion factor of 6834 has been obtained by considering the correction due to multiple scattering effects on the fiber filter of the instrument [18]. In the calculation of extinction coefficient, the aethalometer data are interpolated for obtaining the pertinent values at the wavelengths of the nephelometer $(450,550$, and $700 \mathrm{~nm})$. It is well known that the information on aerosol size distribution can be inferred from the wavelength dependence of the extinction coefficient. Practically the following equation is employed to calculate the value of the Angstrom exponent (AE) [10] [19] [20] [21] [22]:

$$
q=-\ln \left[\frac{\alpha_{e x t}^{S}\left(\lambda_{2}\right)}{\alpha_{e x t}^{S}\left(\lambda_{1}\right)}\right] / \ln \left(\frac{\lambda_{2}}{\lambda_{1}}\right) .
$$

This equation can easily be extended for fitting the extinction values observed at more than two wavelengths. The value of $q$ is of the order of unity, and the value becomes larger (smaller) for the dominance of fine-mode (coarse-mode) particles [23] [24] [25]. For example, a high value of AE around 2.0 means the loading of fine mode particles, usually from anthropogenic activities, while a small value around 0.5 indicates the dominance of coarse mode particles such as sea salt. 
When calculating the AE from the sampling data, the following two corrections must be applied before the use of Equation (3). The first correction is usually called the truncation error, which accounts for the loss of signal intensity due to relatively coarse particles [26]. This loss occurs because of first, the aerodynamic loss during the sampling procedure, and second, the limited range of the acceptance angle (between $7^{\circ}$ and $170^{\circ}$ ) of the scattering measurement of the nephelometer (TSI3563). The magnitude of this error can be estimated by examining the correlation between the optical and sampling values of $\alpha_{\text {ext }}$ at 550 nm under relatively dry conditions (with the ambient relative humidity $(R H)$ below $\sim 50 \%$, see below). The second correction is ascribed to the aerosol growth/evaporation process with the change of $R H$. The scattering volume of TSI 3563 is kept relatively warm and dry to avoid the potentially harmful deformation inside the instrument. When particles are sampled from the ambient atmosphere with relatively high $R H$, the diameter of each of hygroscopic aerosol particles reduces rapidly, resulting in a smaller value of scattering cross-section. Thus, to convert the measured value of the scattering coefficient, $\alpha_{\text {ext }}^{S}(\lambda)$, into the ambient value, the following factor is multiplied by the measured scattering coefficient:

$$
f(R H, \lambda)=\frac{\sigma(R H, \lambda)}{\sigma\left(R H_{d r y}, \lambda\right)} .
$$

Here $\sigma(R H, \lambda)$ is the aerosol scattering cross-section at the wavelength $\lambda$ under an ambient $R H$, whereas $\sigma\left(R H_{d r y}, \lambda\right)$ is that under the dry condition inside the instrument. Because of the hysteresis behavior of aerosol growth/evaporation process [27], the value of the enhancement factor, $f(R H, \lambda)$, is close to unity for $R H<50 \%$, and a rapid increase of the value is seen for $R H$ approaching $100 \%$. The dependence of $f(R H, \lambda)$ on $R H$ has been reported, for instance, for five European sites [4], North China plain [5], and southern Spain [6].

From the data of visibility meter, on the other hand, the extinction coefficient at $550 \mathrm{~nm}$ can be calculated by using the Koschmeider equation with the attenuation ratio of $5 \%$ [28]. By combining the wavelength dependence and subtracting the Rayleigh contribution, we obtain

$$
\alpha_{\text {ext }}^{O}(\lambda)=\frac{K_{a}}{V}\left(\frac{\lambda}{550}\right)^{-q}-\frac{P T_{0}}{T P_{0}}\left(1.095 \times 10^{-5}\right)\left(\frac{\lambda}{550}\right)^{-4.05}
$$

Here, $\lambda$ is in units of nanometer, the superscript $O$ indicates the value from the optical measurement, and $K_{\mathrm{a}}=\ln (1 / 0.05)=2.996$ is the Koschmieder coefficient [29]. The second term on the right hand side of Equation (5) is the correction of the contribution of molecule Rayleigh scattering by the approximation formula of Dutton et al. [19], with the pressure $P$ and temperature $T$ as compared with their standard values $\left(P_{0}=1013.25 \mathrm{hPa}\right.$ and $\left.T_{0}=288.15 \mathrm{~K}\right)$.

The value of AOT can be calculated on the basis of $\alpha_{\text {ext }}^{O}(\lambda)$ given by Equation (5). If we assume that the aerosol vertical distribution is given by a simple 
exponential profile with a scale height of $h_{a}$, the value of AOT $\left(\tau_{a}\right)$ can readily be calculated as

$$
\tau_{a}(\lambda)=\alpha_{e x t}^{O}(\lambda) \int_{0}^{\infty} \exp \left(-\frac{z}{h_{a}}\right) \mathrm{d} z=h_{a} \alpha_{e x t}^{O}(\lambda) .
$$

In the actual situation, the aerosol profile shows some deviation from this simple exponential formula. Thus, we employ the extinction profile observed with the vertical lidar (NIES lidar) to estimate the effective value of $h_{a}$. It is noted that the resulting value reflects the altitude dependence of AEC, but it is not sensitive to the choice of the lidar ratio (the ratio between the extinction and back-scattering coefficients) used for solving the lidar data. By combining Equations (5) and (6), we obtain

$$
\tau_{a}(\lambda)=\frac{K_{a} h_{a}}{V}\left(\frac{\lambda}{550}\right)^{-q}-\frac{P}{P_{0}}\left(9.88 \times 10^{-3}\right)\left(\frac{\lambda}{550}\right)^{-4.05} .
$$

Here the second term has been adopted from the approximation formula of Dutton et al. [19] [30].

\section{Results and Discussion}

The proposed methodology is applied to two cases of observation periods of March 19-20, 2017 and May 19-21, 2017, representing relatively low and high $R H$, respectively. The temporal changes of ambient $R H$ and $R H$ inside the nephelometer are plotted for these two cases in Figure 2. From the multi-wavelength data of scattering and absorption coefficients of the nephelometer and aethalometer, respectively, we calculate the real-time values of AEC with AE. By using the AE and visibility data, AOT is calculated for seven wavelengths that correspond to the wavelengths of the skyradiometer $(340,380,400,500,675$, 870 , and $1020 \mathrm{~nm}$ ).

Figure 3 shows the plot that has been used to evaluate the truncation correction by comparing the AEC from sampling instruments (horizontal axis) and the corresponding value obtained from the visibility-meter measurement (vertical axis). Each data point represents the average over $10 \mathrm{~min}$, and the combined data for the two time periods (March 19-20 and May 19-21, 2017) are plotted together. From the sampling measurements, the values of AEC at $550 \mathrm{~nm}$ have been calculated using Equation (1) by adding the nephelometer-derived scattering coefficient and aethalometer-derived absorption coefficient. The measured value of visibility, on the other hand, is converted to AEC using Equation (5). By using the obtained relation of $y=1.15 x+0.05$, one can convert the sampling-based AEC $(x)$ to the ambient (i.e., optical) value of AEC $(y)$ to take account of the truncation error correction. Although this relation is derived for the wavelength of $550 \mathrm{~nm}$, we assume that the same correction can be applicable to wavelengths other than $550 \mathrm{~nm}$.

Figure 4 shows the temporal change of the correction factor, $f(R H)$, given by Equation (4) plotted for the high- $R H$ time period of May 19-21, 2017. Here the 


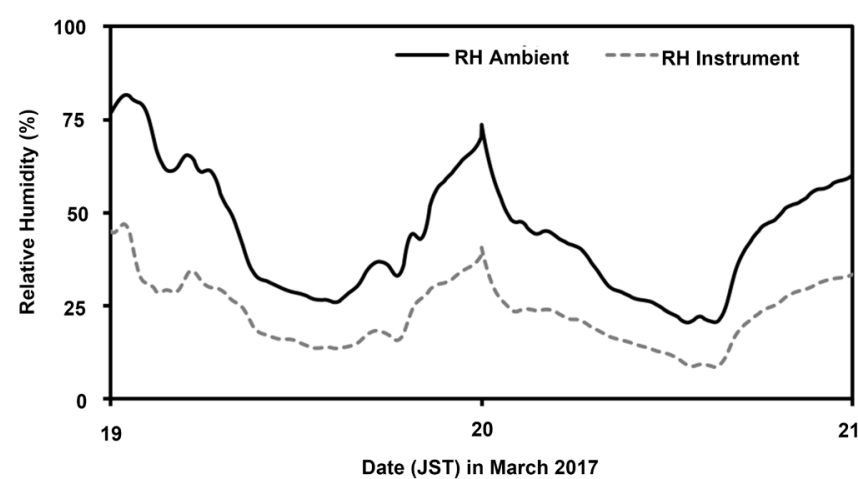

(a)

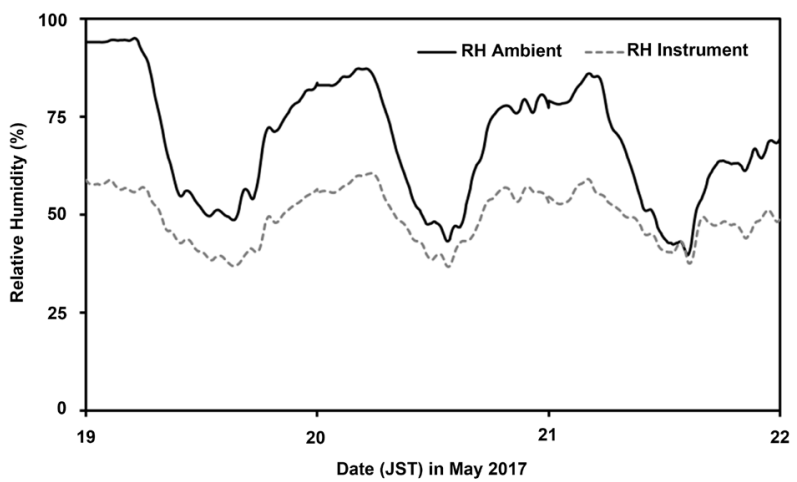

(b)

Figure 2. Temporal change of relative humidity on (a) March 19-20, 2017 and (b) May 19-21, 2017. The values of ambient and instrumental $R H$ are derived from the weather monitor and nephelometer, respectively.

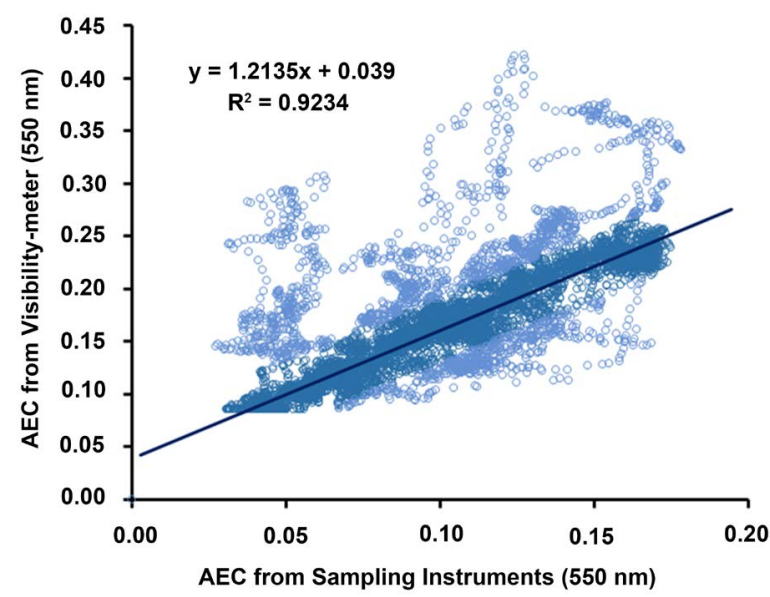

Figure 3. Comparison of AEC between the sampling measurement $(x)$ and the optical masurement $(y)$ to evaluate the influence of the truncation erro correction of the sampling procedure. All the data for the two periods of March 19-20 and May 19-21, 2017 are combined together. Points in dark blue are used for deriving the regression equation between $x$ and $y$, while those in light blue are considered as outliers.

ambient value of the aerosol scattering coefficient has been calculated as the difference between the extinction coefficient from the visibility meter and the absorption coefficient from the aethalometer, while the dry scattering coefficient is obtained directly from the scattering coefficient of the nephelometer. This correction factor is applied only to the higher $R H$ : no $f(R H)$ correction is considered to the low $R H$ case in March 19-20, 2017.

Figure 5 and Figure 6 show that the temporal change of AEC derives from the sampling (nephelometer, aethalometer) and optical (visibilitymeter) measurements, in comparison with the time-height indicator plot of extinction coefficient derives from the NIES-lidar. Figure 5 shows the results for the lower $R H$ case of March 19-20, 2017. The original values of AEC are shown in Figure 5(a). In this panel, it is apparent that the sampling-based AEC value for $550 \mathrm{~nm}$ is too 


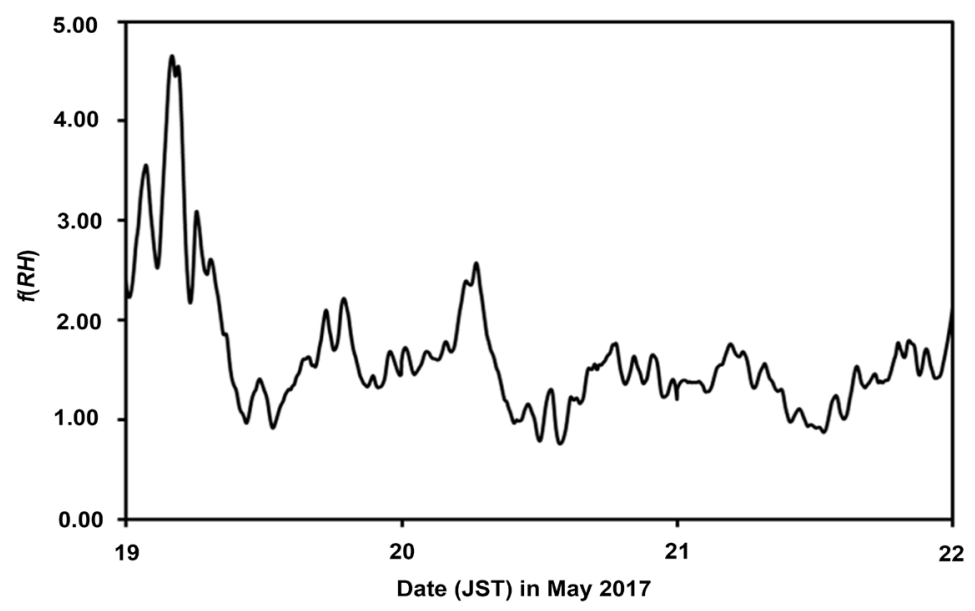

Figure 4. Temporal change of the correction factor of $f(R H)$ calculated for the case of higher $R H$ in May 19-21, 2017.

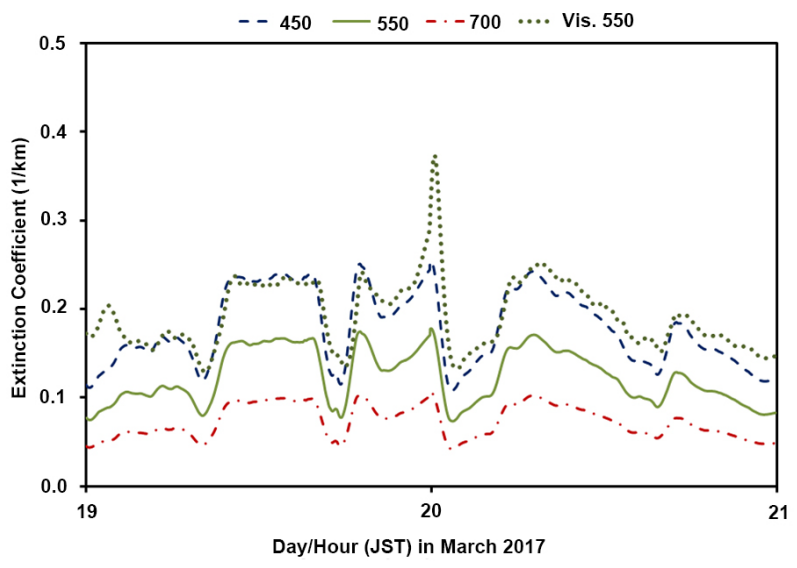

(a)

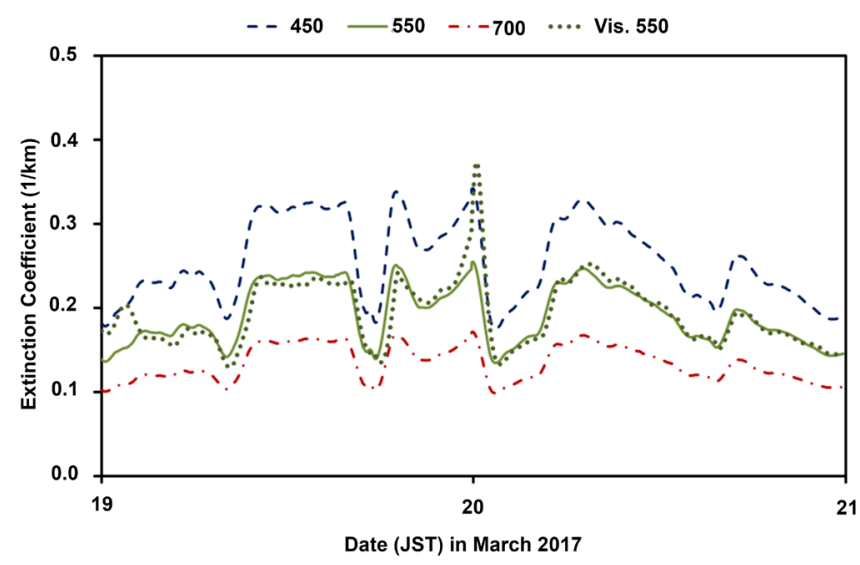

(b)

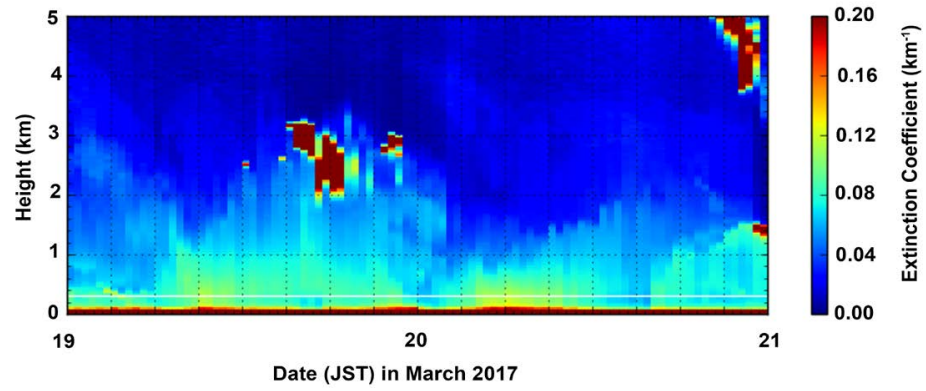

(c)

Figure 5. Temporal change of AEC observed in the low $R H$ case of March 19-20, 2017: (a) before correction, (b) after applying the truncation correction, and (c) the time-height indicator representation of the vertical lidar data.

small as compared with the optically measured value. The AEC values after correcting the truncation error are shown in Figure 5(b), in which a good agreement is found between the sampling and optical (visibility) AEC at the same wavelength of $550 \mathrm{~nm}$. Figure 6 shows the results obtained for the higher $R H$ 


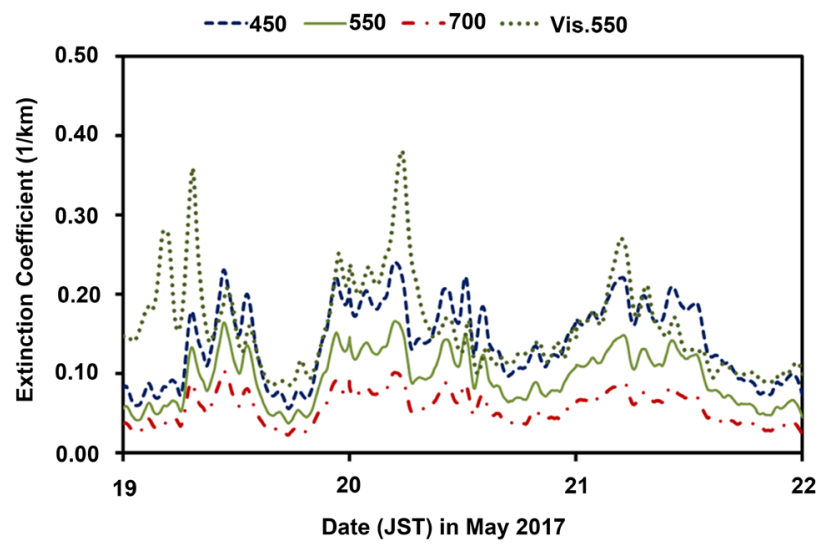

(a)

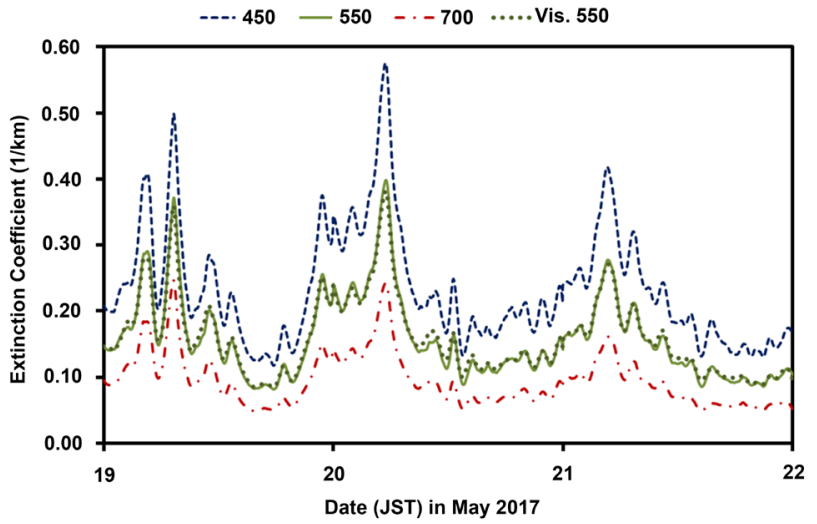

(c)

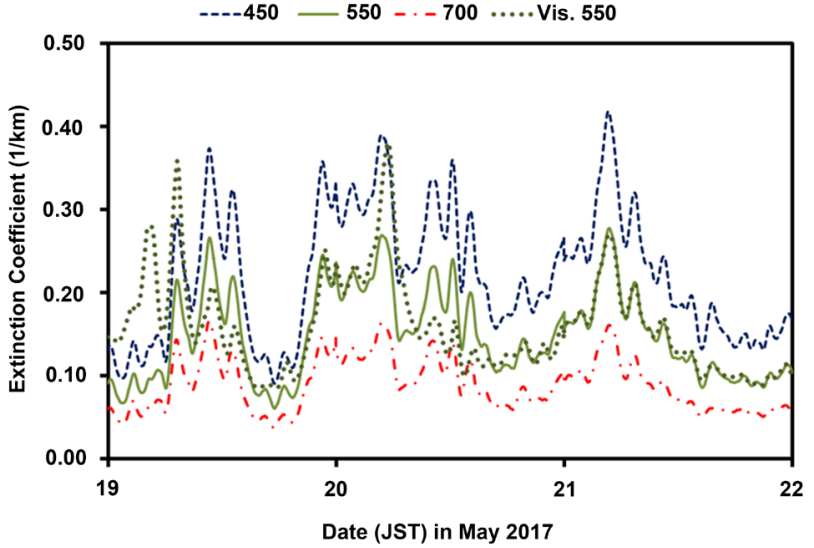

(b)

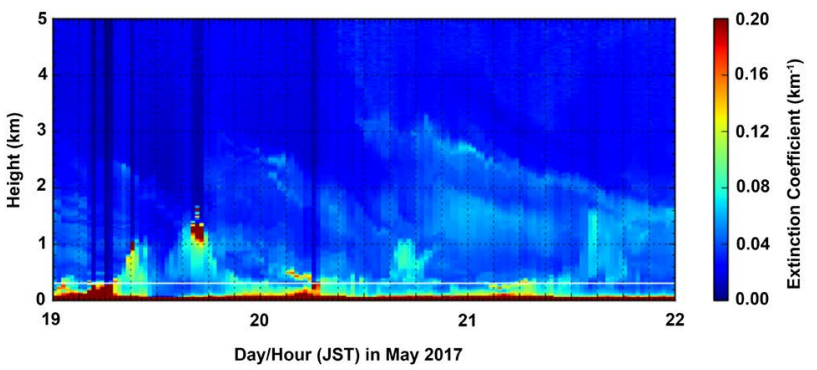

(d)

Figure 6. Temporal change of AEC in the high $R H$ case of May 19-21, 2017: (a) before correction, (b) after applying the truncation correction, (c) after further applying the $f(R H)$ correction and (d) the time-height indicator representation of the vertical lidar data.

case observed on May 19-21, 2017. The original values of AEC are shown in Figure 6(a). The temporal change of AEC after correcting the truncation error is shown in Figure 6(b), in which occasional deviations are seen between the sampling and optical data. A better agreement can be seen in Figure 6(c), which indicates the result after further applying the $f(R H)$ correction.

In Figure 5(c) and Figure 6(d), the time-height indicator representation of AEC is displayed as derived from the NIES-lidar observation at $532 \mathrm{~nm}$. Here, we have applied the Fernald method [31] [32] for processing the backscattering signal of lidar data by assuming alidar ratio of $50 \mathrm{sr}$ after considering procedures in refs [33] [34] [35]. In both March and May cases, the temporal change of AEC near the surface level (up to $0.5 \mathrm{~km}$ from the ground) shows good similarity with the results shown in Figure 5(b) and Figure 6(c). When calculating the AOT by means of Equation (7), we derive the values of $\mathrm{AE}$ from the results shown in Figure 5(b) and Figure 6(c), and the effective value of the aerosol scale height, $h_{a}$, from the vertical lidar data shown in Figure $5(\mathrm{c})$ and Figure $6(\mathrm{~d})$. It is emphasized that the value of $h_{a}$ is determined by the vertical profile of AEC, and the value is not critically dependent on the assumed value of the lidar ratio. 
Figure 7 shows the comparison of AE between the AEC from the sampling (nephelometer + aethalometer) measurement and AOT from the optical (sunphotometer) measurement. Since the resulting values of AE are relatively stable regardless of the atmospheric conditions including $\mathrm{RH}$, the influence of truncation correction can be estimated by combining the best data in the low and high $R H$ data observed on March 19-20 and May 19-20, 2017, respectively. For calculating the values of AOT, the calibration procedure based on the Langley extrapolation method [10] [19] has been applied using the data observed under very small aerosol loading (February 12, 2017).

Figure 8 shows the temporal change of AE derived from the AEC values of sampling instruments shown in Figure 5(b) and Figure 6(c). Here we employ the three wavelengths of 450, 550, and $700 \mathrm{~nm}$ for computing AE values. In Figure 8, the curves denoted "before correction" show the AE values just estimated from the raw data of sampling measurement. The curves denoted "after correction" show the results after applying the truncation correction (for both Figure $8(\mathrm{a})$ and Figure $8(\mathrm{~b})$ ) as well as the $f(R H)$ correction (Figure $8(\mathrm{~b})$ ). Obviously, the advantage of the present method is that the derivation of AE can be extended to 24-hours, since the sampling and visibility measurements are conducted continuously. The corrected values of AE in Figure 8(a) and Figure 8(b) can be compared with the independent values of $\mathrm{AE}$ from skyradiometer and sunphotometer (Figure 8(c) and Figure 8(d)). Since the skyradiometer and sunphotometer values are affected also from the aerosol properties in the free troposphere [16] [30], their AE values tend to be somewhat ( 0.1) higher than the values estimated from the sampling instruments.

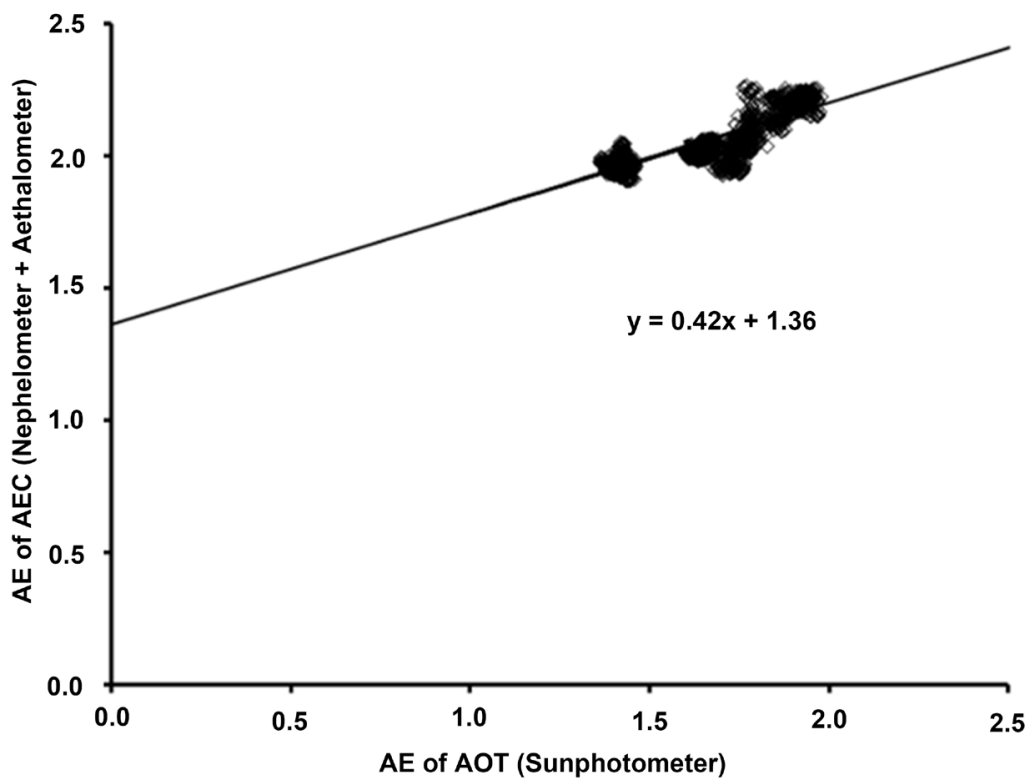

Figure 7. Comparison of the values of AE between the AEC obtained from sampling (nephelometer + aethalometer) and AOT derived from optical (sunphotometer) measurements at daytime and nearly cloud free conditions during March 19-20 and May 19-21, 2017. 


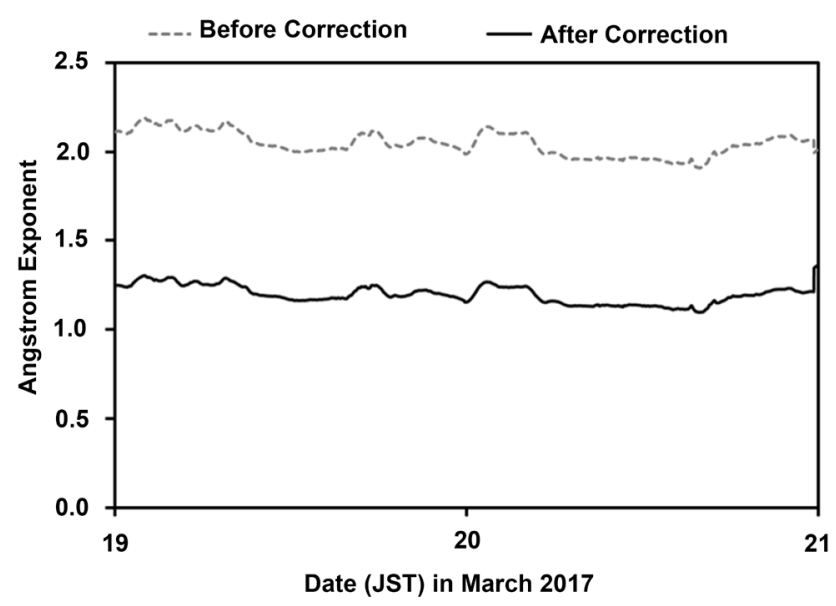

(a)

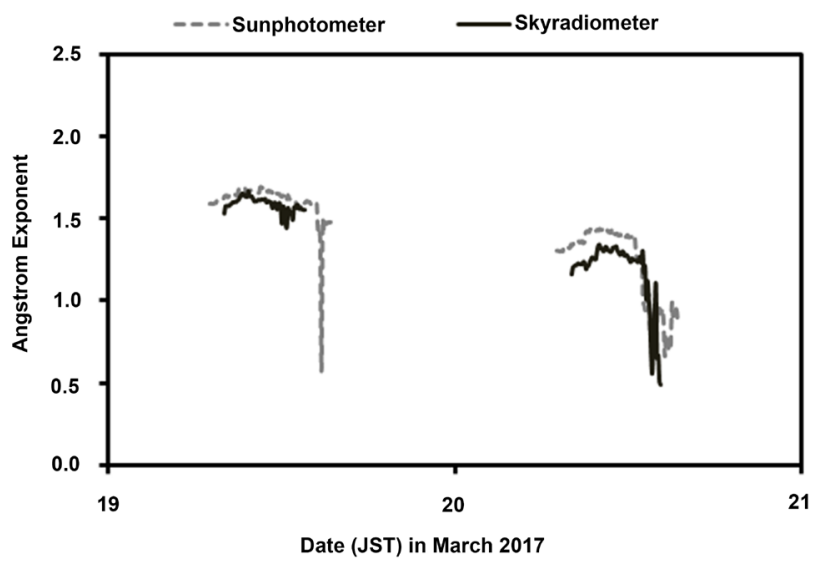

(c)

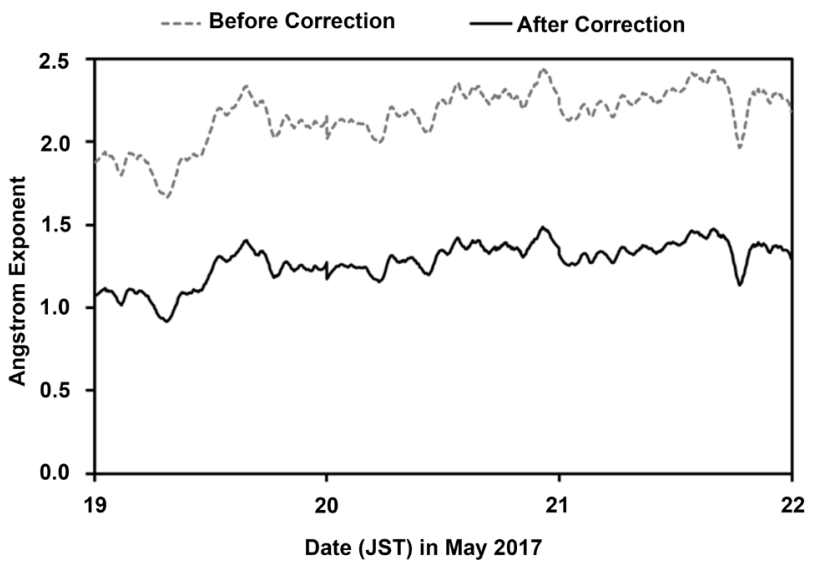

(b)

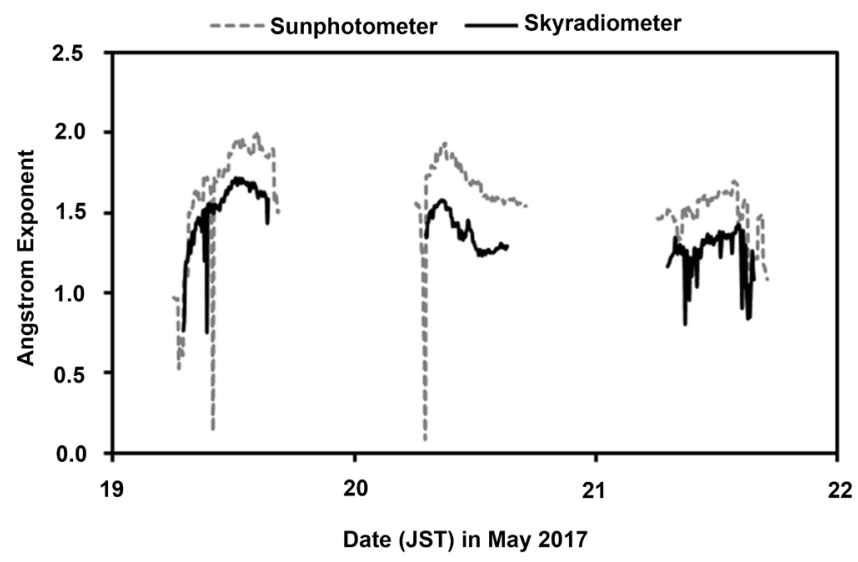

(d)

Figure 8. Temporal change of the AE obtained before and after correction in (a) March 19-20, 2017 and (b) May 19-21, 2017 as representation of the lower and higher relative humidity, respectively.

Figure 9 and Figure 10 show the estimated results of AOT for the two time periods in March and May 2017, respectively. The AOT values are computed for the following seven wavelengths, namely, ultraviolet ( 340 and $380 \mathrm{~nm}$ ), blue (400 $\mathrm{nm})$, green $(500 \mathrm{~nm})$, red $(675 \mathrm{~nm})$, and near infrared $(870$ and $1020 \mathrm{~nm})$. These wavelengths have been selected in consideration of the wavelengths of the sunphotometer $(368,500,675$, and $778 \mathrm{~nm})$ and the skyradiometer $(340,380,400$, $500,675,870$, and $1020 \mathrm{~nm}$ ). In each figure, panel (a) shows the uninterrupted values of AOT throughout day- and night-time estimated using Equation (7). In panels (b) and (c), on the other hand, the AOT values of independent measurements using the skyradiometer and sunphotometer are plotted during the daytime under near cloud-free conditions.

In the low $R H$ case during March 19-20, 2017, the AOT curves resulted from the coupled analysis of the sampling and visibility-meter data show similar behavior to the skyradiometer, indicating relatively stable condition in relation to low $R H$. On March 19, the value of AOT at $500 \mathrm{~nm}$ from the optical measurement (skyradiometer and sunphotometer, Figure $9(\mathrm{~b})$ and Figure $9(\mathrm{c})$ ) is larger 


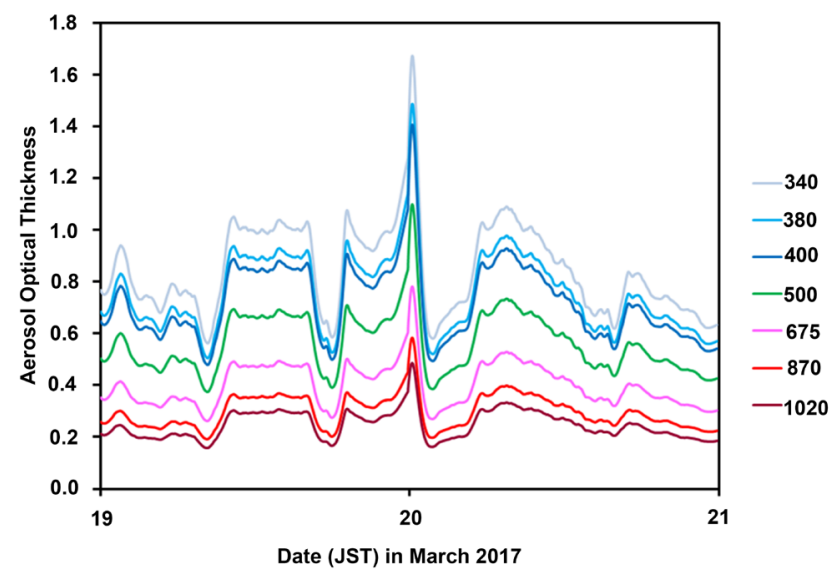

(a)

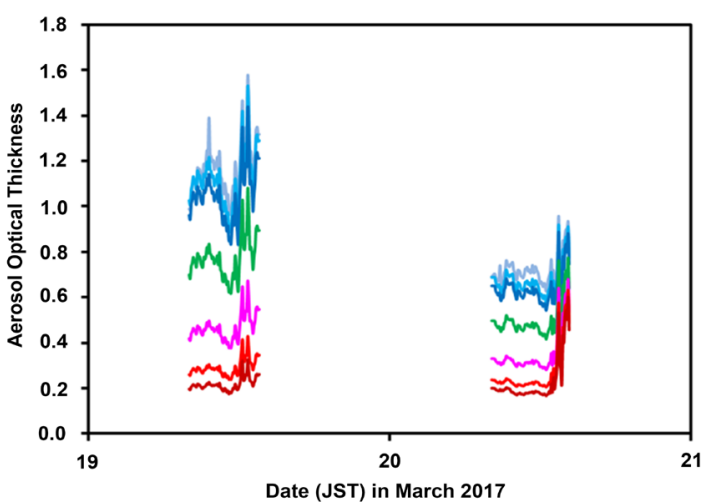

(c)
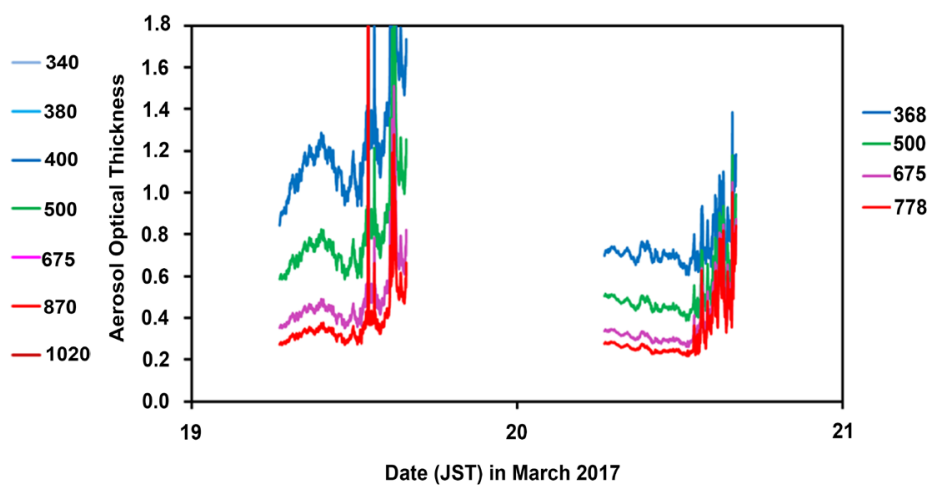

(d)

Figure 9. Temporal change of the AOT for the low $R H$ case of March 19-21, 2017: (a) uninterrupted estimation based on the sampling and visibility measurements, (b) skyradiometer AOT observed during daytime, near-cloud free condition, and (c) sunphotometer AOT.

by $\sim 0.1$ than that estimated from the sampling (Figure 9(a)). Presumably, this difference is ascribable to the contribution from the free troposphere, since the sampling measurement represents the aerosol properties inside the atmospheric boundary layer. On March 20, the decreasing trend found in Figure 9(a) is not seen in Figure 9(b) and Figure 9(c), since both the skyradiometer and sunphotometer are affected by cloud effects that became apparent in late afternoon.

The temporal variation of AOT in the case of high $R H$ (Figure 10), on the other hand, is more fluctuating, though some similarity is seen between the sampling (Figure 10(a)) and optical (Figure 10(b) and Figure 10(c)) measurements, especially on the occurrence of peak positions. For this high $R H$ case, the observed fluctuating behavior can be ascribed mainly to the correction due to the $f(R H)$ effect, the magnitude of which can be variable in association with the fraction of hygroscopic aerosol species [4] [5] [6]. Such a behavior can also be seen in AEC at the surface level, since the AOT is the multiplication between attenuation of light (extinction coefficient) and the range of light propagation [9] [10] [19]. From the overall procedure, we can estimate the AE and AOT values from the sampling data, with approximately 5\% accuracy for $\mathrm{AE}$ and $10 \%$ 


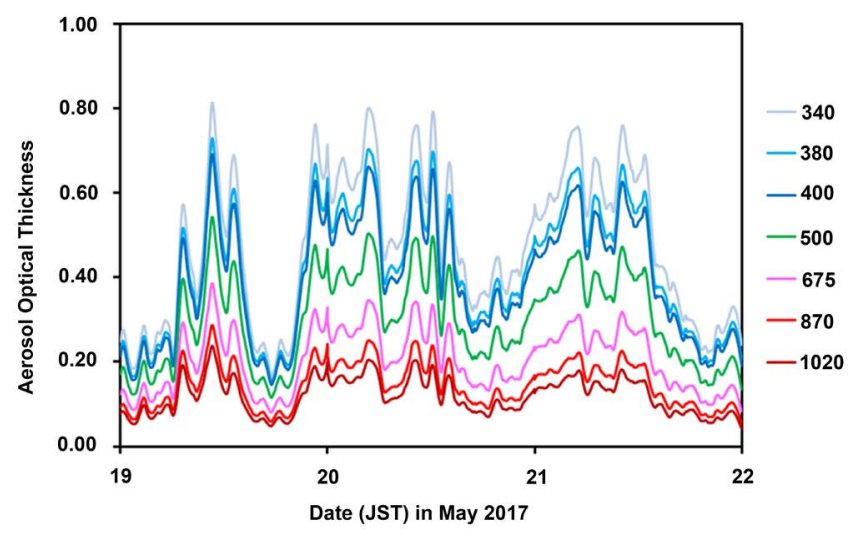

(a)

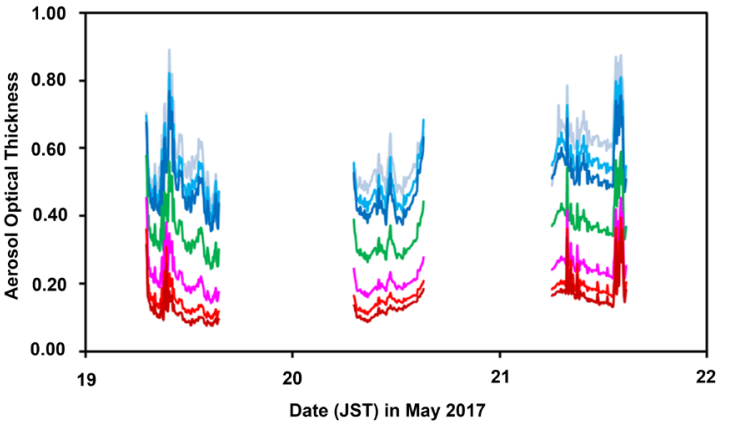

(b)

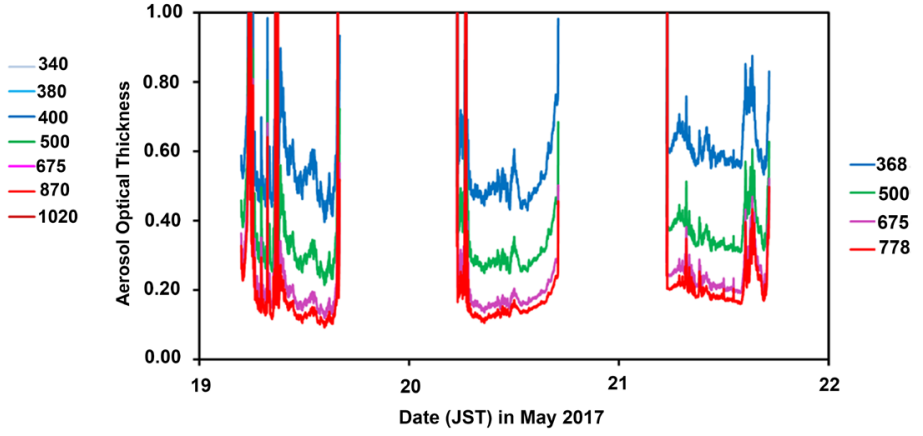

(c)

Figure 10. Temporal change of the AOT for the high $R H$ case of May 19-22, 2017: (a) uninterrupted estimation based on the sampling and visibility measurements, (b) skyradiometer AOT observed during daytime, near cloud-free condition, and (c) sunphotometer AOT that shows more influence of cloud optical thickness (i.e., less screening).

accuracy for AOT. Such a capability will be useful for studying aerosol properties throughout 24-hours regardless of the solar radiation and cloud coverage.

\section{Conclusion}

A novel methodology of estimating AOT from continuous data of ground-based sampling instruments (an integrating nephelometer and an aethalometer) and a visibility meter have been proposed and demonstrated. The vertical profile of AEC has been derived from an ancillary data observed with a Mie-scattering lidar. In order to convert the value of aerosol scattering coefficient measured with a nephelometer to ambient value in the atmospheric boundary layer, the correction of the truncation error has to be applied. The magnitude of this error has been successfully evaluated by comparing the nephelometer (sampling) data and visibility-meter (optical) data. Under high $R H$ conditions, an additional correction that arises from the evaporation of hygroscopic particles inside the instrument (nephelometer) has to be taken into account. In the present work, we have evaluated the value off $(R H)$ from the comparison between the visibility-meter-derived AEC and the raw data of the sampling measurement. The temporal change of the estimated AOT has been compared with the observed value from either a sunphotometer or a skyradiometer. It has been found that 
relatively stable estimation is feasible for the case of relatively low $R H$ situation, though more fluctuating behavior of AOT is seen for relatively high $R H$ case. The present approach will be generally useful to estimate the optical properties of ambient aerosols on the basis of ground-based sampling data. The capability of uninterrupted estimation of AOT will provide new insight in the source and sink investigation of aerosols as well as in monitoring local environment.

\section{Acknowledgements}

The first author (JA) would like to thank to Ministry of Research, Technology, and Higher Education Republic of Indonesia for supporting fellowship named Beasiswa Dikti.

\section{References}

[1] Seinfeld, H. and Pandis, S. (1998) Atmospheric Chemistry and Physics, from Air Pollution to Climate Change. John Wiley \& Sons, New York.

[2] IPPC (2007) Climate Change 2007 : The Physical Science Basis. Geneva.

[3] Kuze, H. (2012) Multi-Wavelength and Multi-Direction Remote Sensing of Atmospheric Aerosols and Clouds, Remote Sensing-Applications. InTech Publication, 279-294.

https://www.intechopen.com/books/remote-sensing-applications/multi-wavelength -and-multi-direction-remote-sensing-of-atmospheric-aerosols-and-clouds

[4] Zieger, P., Fierz-Schmidhauser, R., Weingartner, E. and Baltensperger, U. (2013) Effects of Relative Humidity on Aerosol Light Scattering: Results from Different European Sites. Atmospheric Chemistry and Physics, 13, 10609-10631. https://doi.org/10.5194/acp-13-10609-2013

[5] Titos, G., Lyamani, H., Cazorla, A., Sorribas, M., Foyo-Moreno, I., Wiedensohler, A. and Alados-Arboledas, L. (2014) Study of the Relative Humidity Dependence of Aerosol Light-Scattering in Southern Spain. Tellus B: Chemical and Physical Meteorology, 66, 1-15.

[6] Chen, J., Zhao, C.S., Ma, N. and Yan, P. (2014) Aerosol Hygroscopicity Parameter Derived from the Light Scattering Enhancement Factor Measurements in the North China Plain. Atmospheric Chemistry and Physics, 14, 8105-8118. https://doi.org/10.5194/acp-14-8105-2014

[7] Chung, C.E. (2012) Aerosol Direct Radiative Forcing: A Review. InTech Publication, 379-394.

https://www.intechopen.com/books/atmospheric-aerosols-regional-characteristicschemistry-and-physics/aerosol-direct-radiative-forcing-a-review

[8] Shaw, G.E. (1983) Sun Photometry. Bulletin of the American Meteorological Society, 64, 4-10. https://doi.org/10.1175/1520-0477(1983)064<0004:SP >2.0.CO;2

[9] Qiu, J. (1998) A Method to Determine Atmospheric Aerosol Optical Depth Using Total Direct Solar Radiation. Journal of the Atmospheric Sciences, 55, 744-757.

[10] Cerqueira, J.G., Fernandez, J.H., Hoelzemann, J.J., Leme, N.M.P. and Sousa, C.T. (2014) Langley Method Applied in Study of Aerosol Optical Depth in the Brazilian Semiarid Region Using 500, 670 and 870 nm Bands for Sun Photometer Calibration. Advances in Space Research, 54, 1530-1543.

https://doi.org/10.1016/j.asr.2014.06.006 
[11] Chen, W.N., Chen, Y.W., Chou, C.C.K., Chang, S.Y., Lin, P.H. and Chen, J.P. (2009) Columnar Optical Properties of Tropospheric Aerosol by Combined Lidar and Sunphotometer Measurements at Taipei, Taiwan. Atmospheric Environment, 43, 2700-2708. https://doi.org/10.1016/j.atmosenv.2009.02.059

[12] Chubarova, N.Y., Poliukhov, A.A. and Gorlova, I.D. (2016) Long-Term Variability of Aerosol Optical Thickness in Eastern Europe over 2001-2014 according to the Measurements at the Moscow MSU MO AERONET Site with Additional Cloud and $\mathrm{NO}_{2}$ Correction. Atmospheric Measurement Techniques, 9, 313-334. https://doi.org/10.5194/amt-9-313-2016

[13] Sasano, Y. (1996) Tropospheric Aerosol Extinction Coefficient Profiles Derived from Scanning Lidar Measurements over Tsukuba, Japan, from 1990 to 1993. Applied Optics, 35, 4941-4952. https://doi.org/10.1364/AO.35.004941

[14] Fukagawa, S., Kuze, H., Bagtasa, G., Naito, S., Yabuki, M., Takamura, T. and Takeuchi, N. (2006) Characterization of Seasonal Variation of Tropospheric Aerosols in Chiba, Japan. Atmospheric Environment, 40, 2160-2168. https://doi.org/10.1016/j.atmosenv.2005.11.056

[15] Manago, N., Miyazawa, S., Bannu and Kuze, H. (2011) Seasonal Variation of Tropospheric Aerosol Properties by Direct and Scattered Solar Radiation Spectroscopy. Journal of Quantitative Spectroscopy and Radiative Transfer, 112, 285-291. https://doi.org/10.1016/j.jqsrt.2010.06.015

[16] Holben, B.N., Eck, T.F., Slutsker, I., Tanré, D., Buis, J.P., Setzer, A., Vermote, E. Reagan, J.A., Kaufman, Y.J., Nakajima, T., Lavenu, F., Jankowiak, I. and Smirnov, A. (1998) AERONET-A Federated Instrument Network and Data Archive for Aerosol Characterization. Remote Sensing of Environment, 66, 1-16. https://doi.org/10.1016/S0034-4257(98)00031-5

[17] Hashimoto, M., Nakajima, T., Dubovik, O., Campanelli, M., Che, H., Khatri, P., Takamura, T. and Pandithurai, G. (2012) Development of a New Data-Processing Method for SKYNET Sky Radiometer Observations. Atmospheric Measurement Techniques, 5, 2723-2737. https://doi.org/10.5194/amt-5-2723-2012

[18] Müller, T., Henzing, J.S., De Leeuw, G. Wiedensohler, A., Alastuey, A., Angelov, H., Bizjak, M., Collaud Coen, M., Engström, J.E., Gruening, C., Hillamo, R., Hoffer, A., Imre, K., Ivanow, P., Jennings, G., Sun, J.Y., Kalivitis, N., Karlsson, H., Komppula, M., Laj, P., Li, S.M., Lunder, C., Marinoni, A., Martins Dos Santos, S., Moerman, M., Nowak, A., Ogren, J.A., Petzold, A., Pichon, J.M., Rodriquez, S., Sharma, S., Sheridan, P.J., Teinilä, K., Tuch, T., Viana, M., Virkkula, A., Weingartner, E., Wilhelm, R. and Wang, Y.Q. (2011) Characterization and Intercomparison of Aerosol absorption Photometers: Result of Two Intercomparison Workshops. Atmospheric Measurement Techniques, 4, 245-268. https://doi.org/10.5194/amt-4-245-2011

[19] Bodhaine, B.A., Wood, N.B., Dutton, E.G. and Slusser, J.R. (1999) On Rayleigh Optical Depth Calculations. Journal of Atmospheric and Oceanic Technology, 16, 1854-1861.

[20] Soni, K., Singh, S., Bano, T., Tanwar, R.S. and Nath, S. (2011) Wavelength Dependence of the Aerosol Angstrom Exponent and Its Implications over Delhi, India. Aerosol Science and Technology, 45, 1488-1498. https://doi.org/10.1080/02786826.2011.601774

[21] Tijjani, B.I. and Uba, S. (2012) Dependence of the Angstrom Exponents on Wavelength and Relative Humidities for Four Types of Aerosols. International Journal of Research and Revies in Applied Sciences, 2, 1085-1102.

[22] Jung, C.H., Um, J., Lee, J.Y. and Kim, Y.P. (2013) Sensitivity Analysis of the 
Angstrom Exponent for Multimodal Aerosol Size Distributions. Asia-Pacific Journal of Atmospheric Sciences, 49, 625-634.

[23] Kaufman, Y.J., Fraser, R.S. and Mahoney, R.L. (1991) Fossil Fuel and Biomass Burning Effect on Climate-Heating or Cooling? Journal of Climate, 4, 578-588. https://doi.org/10.1175/1520-0442(1991)004<0578:FFABBE >2.0.CO;2

[24] Eck, T.F., Holben, B.N., Reid, J.S., Dubovik, O., Smirnov, A., O’Neill, N.T., Slutsker, I. and Kinne, S. (1999) Wavelength Dependence of the Optical Depth of Biomass Burning, Urban, and Desert Dust Aerosols. Journal of Geophysical Research, 104, 31333-31349. https://doi.org/10.1029/1999JD900923

[25] Dubovik, O., Holben, B., Eck, T.F., Smirnov, A., Kaufman, Y.J., King, M.D., Tanré, D. and Slutsker, I. (2002) Variability of Absorption and Optical Properties of Key Aerosol Types Observed in Worldwide Locations. Journal of the Atmospheric Sciences, 59, 590-608. https://doi.org/10.1175/1520-0469(2002)059<0590:VOAAOP >2.0.CO;2

[26] Anderson, T.L. and Ogren, J.A. (1998) Determining Aerosol Radiative Properties Using the TSI 3563 Integrating Nephelometer. Aerosol Science and Technology, 29, 57-69. https://doi.org/10.1080/02786829808965551

[27] Tang, I.N. (1996) Chemical and Size Effects of Hygroscopic Aerosols on Light Scattering Coefficients. Journal of Geophysical Research: Atmospheres 101, 19245-19250. https://doi.org/10.1029/96JD03003

[28] Penndorf, R. (1957) Tables of the Refractive Index for Standard Air and the Rayleigh Scattering Coefficient for the Spectral Region between 0.2 and $20.0 \mu$ and Their Application to Atmospheric Optics. Journal of the Optical Society of America, 47, 176-186. https://doi.org/10.1364/JOSA.47.000176

[29] Winstanley, J.V. and Adams, M.J. (1975) Point Visibility Meter: A Forward Scatter Instrument for the Measurement of Aerosol Extinction Coefficient. Applied Optics, 14, 2151-2157. https://doi.org/10.1364/AO.14.002151

[30] Dutton, E., Reddy, P., Ryan, S. and DeLuisi, J.J. (1994) Features and Effects of Aerosol Optical Depth Observed at Mauna Loa, Hawaii: 1982-1992. Journal of Geophysical Research, 99, 8295-8306. https://doi.org/10.1029/93JD03520

[31] Klett, J.D. (1985) Lidar Inversion with Variable Backscatter/Extinction Ratios. Applied Optics, 24, 1638-1643. https://doi.org/10.1364/AO.24.001638

[32] Fernald, F.G., (1984) Analysis of Atmospheric Lidar Observations: Some Comments. Applied Optics, 23, 652-653. https://doi.org/10.1364/AO.23.000652

[33] Kinjo, H., Kuze, H., Takamura, T., Yabuki, M. and Takeuchi, N. (2001) Determination of Aerosol Extinction-to-Backscattering Ratio from Multiwavelength Lidar Observation. Japanese Journal of Applied Physics, 40, 434-440. https://doi.org/10.1143/JJAP.40.434

[34] Yabuki, M., Kuze, H., Kinjo, H. and Takeuchi, N. (2003) Determination of Vertical Distributions of Aerosol Optical Parameters by Use of Multi-Wavelength Lidar Data. Japanese Journal of Applied Physics, 42, 686-694. https://doi.org/10.1143/JJAP.42.686

[35] Mabuchi, Y., Manago, N., Bagtasa, G., Saitoh, H. Takeuchi, N., Yabuki, M., Shiina, T. and Kuze, H. (2012) Multi-Wavelength Lidar System for the Characterization of Tropospheric Aerosols and Clouds. 2012 IEEE International Geoscience and Remote Sensing Symposium, Munich, 22-27 July 2012, 2505-2508. 